\title{
Article \\ Crack propagation modeling of strengthening of RC deep beams with CFRP plates
}

\author{
Shahriar Shahbazpanahi ${ }^{1}$, Hogr Karim ${ }^{2}$, and Wrya Abdullah ${ }^{3}$, Amir Mosavi 4* \\ 1 Department of Civil Engineering, Sanandaj Branch, Islamic Azad University, Kurdistan, Iran; \\ sh.shahbazpanahi@iausdj.ac.ir (S.S.) \\ 2 Civil Engineering Department, University of Halabja, Halabja, Kurdistan Region, Iraq; hogrka- \\ rim@uoh.edu.iq (H. K.) \\ 3 Civil Engineering Department, College of Engineering, University of Sulaimani, Kurdistan Region, Iraq \\ wrya.faraj@univsul.edu.iq (W. A.) \\ 4 Thuringian Institute of Sustainability and Climate Protection, 07743 Jena, Germany \\ a.mosavi@ieee.org_(A. M.) \\ * Correspondence: a.mosavi@ieee.org
}

\begin{abstract}
Fracture analysis of reinforced concrete deep beam strengthened with carbon fiber-reinforced polymer (CFRP) plates was carried out. The present research aims to find out whether the crack propagation in a strengthened deep beam follows linear elastic fracture mechanics (LEFM) theory or nonlinear fracture mechanics theory. To do so, a new energy release rate based on nonlinear fracture mechanics theory was formulated on the finite element method and the discrete cohesive zone model (DCZM) was developed in deep beams. To validate and compare with numerical models, three deep beams with rectangular cross-sections were tested. The code results based on nonlinear fracture mechanics models were compared with experimental results and ABAQUS results carried out based on LEFM. The predicted values of initial stiffness, yielding point and failure load, energy absorption, and compressive strain in the concrete obtained by the proposed model were very close to the experimental results. However, the ABAQUS software results have greater differences with the experimental results. For example, the predicted failure load for the shear-strengthened deep beam using the proposed model has only $6.3 \%$ differences compared to the experimental result. However, the predicted failure load using ABAQUS software based on LEFM has greater differences (25.1\%) compared to the experimental result.
\end{abstract}

Keywords: CFRP; concrete; deep beam; propagation

\section{Introduction}

Reinforced concrete deep beams play an essential role in bridges, buildings, offshore structures, foundations, and military structures $[1,2,3]$. Pile caps in Foundations, coupling beams in buildings, transfer beams, load-bearing walls, and bunker walls behave as deep beams [4]. In the deep beam, the span to effective depth ratio is less than or equals to 2.0 [5] and the transverse plane sections before bending do not remain plane after bending [6].

In general, cracks in a concrete structure, such as deep beams, start in the tension zone due to increasing stresses or the presence of initial cracks [7]. Therefore, these cracks must be studied properly. Two approaches are existing to study crack propagation in concrete structures [8]. They can be divided into two general categories such as Linear Elastic Fracture Mechanics (LEFM) and nonlinear fracture mechanics theories. LEFM theory, for the first time, was applied to analyze fracture mechanics on ships used in World War II [9]. In the LEFM theory, to calculate the real stress, a factor is multiplied on the stress near ahead of crack which the researchers called it stress intensity factor (SIF). If the principal stress in crack-tip reaches the fracture toughness, the crack propagates. The 
SIF changes with the size of the crack, load, geometry of the structure, and the material properties. One of the most characteristics of LEFM theory is stress singularity at the crack tip. Kaplan's [10]research showed that LEFM theory is not acceptable for normal-sized concrete structures and can be used to investigate the propagation of cracks in mass structures such as concrete dams. Later, researchers found a zone in front of cracks in a normal-sized concrete structure and called it the fracture process zone (FPZ). The behavior of this zone is non-linear and a lot of energy is accumulated in this area that if it exceeds a certain level (fracture energy) the behavior will cause softening [11] [12,13,14]. Modeling of this area is important for concrete structural members, such as beams, joints, and deep beams, and it has been studied in recent years. The FPZ is not used in the LEFM theory $[15,16]$. One of the most successful and accurate methods in modeling this area is the discrete cohesive zone model (DCZM) that was developed in the present study $[17,18,19]$.

On the other hand, by using different kinds of strengthening, the crack propagation of concrete changes. In recent years, Carbon Fiber Reinforced Polymer (CFRP) plates have been applied in concrete structures. Advantages of this type of retrofitting are low weight, corrosion resistant, easy installation, and high tensile strength $[20,21,22]$. Nowadays, strengthening using CFRP is of interest from an economic point of view [23]. The use of CFRP composites is now identified as a successful, suitable, and efficient technique to strengthen structures [24].

Because CFRP plates affect the initiation and propagation of cracks in concrete members, including deep beams, it is necessary to model, test, and study these members. Due to shear crack, the strengthening of deep beams in the shear region is significant. shear cracks propagate more in deep beams compare with flexural cracks.

Although, it was expected in advance that flexural strengthening of a deep beam in the flexural-zone (soffit strengthen of the deep beam) could not enhance their load-displacement behavior. To verify this issue, however, such strengthening was performed in this study. Indeed, capacity of deep beams is rather affected by shear-strengthening (side face of the deep beam) than flexural-strengthening.

There are many experimental works on deep beams and CFRP shear-strengthened deep beams [25,26]. However, there is limited knowledge about crack propagation in a concrete deep beam strengthened with CFRP plates in flexural and shear regions can be found in the literature. It is vital to carry out experimental tests to better understand the crack propagation pattern of concrete deep beams strengthened with CFRP plates.

The present research aims to find out whether the crack propagation in a strengthened deep beam follows LEFM theory or nonlinear fracture mechanics theory. Therefore, a new energy release rate based on nonlinear fracture mechanics theory was formulated using finite element method. In this study, a numerical model was proposed to simulate the FPZ. To validate and compare with the numerical models, three deep beam specimens with rectangular cross-sections were tested. One of the deep beams was considered as a control specimen. Another deep beam was strengthened in flexural with CFRP plats at the bottom and the last one was strengthened in shear with CFRP plates in both sides of the shear span of the beam. The three beams were loaded with two-point monotonic loads until failure. The results of the FEAPpv® program code based on the nonlinear fracture mechanics were compared with experimental results with the results of the FEAPpv ${ }^{\circledR}$ program code based on the nonlinear fracture mechanics model and ABAQUS software based on LEFM..

\section{Materials and Methods}

\subsection{Numerical model}

2.1.1. Proposed numerical model based on nonlinear fracture mechanic

The Finite Element Analysis Programs personal version (FEAPpv) are processor evaluation methods considered for utilizing in an instructional package to show the presence of the platform of elements and simulation. FEAPpv has only command language and designed for research by Taylor [27]. In this program, the solution algorithm is 
written by the operator. Therefore, each operator can describe a solution plan that meets specific needs. The system includes enough commands that can be applied for use in mechanics, structural, heat transfer, fluid, and other areas by differential equations. Several numerical models have been accomplished by FEAPpv [28,29,30,31,32,33].

To estimate shear crack propagation for concrete deep beam, a new formulation of energy release rate based on the finite element method is introduced. To compute the strain energy release, the virtual crack closure technique (VCCT), which is the most popular and powerful tool on DCZM, is used [17]. A small concrete deep beam element in the shear span is shown in Figure 1. A truss element as the interface is set between interfacial node pairs, nodes 1 and 2 . Initially, nodes ' 1 ' and ' 2 ' have the same coordinates.

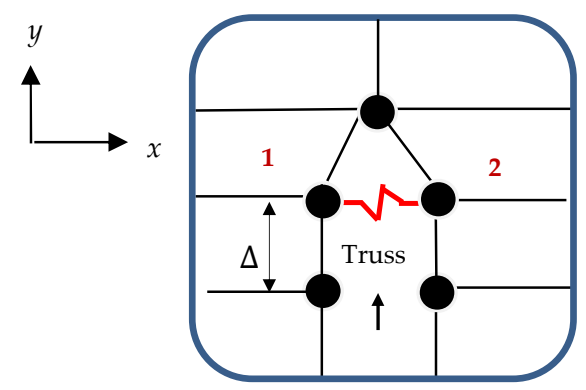

Figure 1. A part of a concrete deep beam

The stiffness of the interface element that selected as truss element, in the elastic zone (no crack propagates) based on VCCT is given by [18]:

$$
\begin{aligned}
& k_{x}=\frac{E B \Delta}{h}, \\
& k_{y}=\frac{G B \Delta}{h},
\end{aligned}
$$

where $E, G, B, \Delta$ and $h$ are Young's modulus of concrete, shear modulus, the width of the deep beam, mesh size, and height of the deep beam, respectively. $k_{x}$, and $k_{y}$ are the stiffness of the interface element in $\mathrm{x}$ and $\mathrm{y}$ directions, respectively. The cracking stress proposed by Thomasa et al. [34] is adopted to model the initial shear crack as:

$$
\sigma_{\text {start }}=0.24 \sqrt{1.25 f_{c}^{\prime}}
$$

where $\sigma_{\text {start }}$ and $f_{c}^{\prime}$ are cracking stress and concrete compressive strength, MPa, respectively. If the principal stress in Node ' 1 ' or ' 2 ' was equal to Eq. (3), the stiffness's in Eqs. (1) and (2) were zero and cracks were created. The normal stress of crack propagation by Walraven [35] is adopted to find strain energy release rates in the deep beam.

$$
\sigma_{N}=C \cdot K \cdot\left(100 \rho f_{c}\right)^{1 / 3},
$$

where $\sigma_{N}, \rho, K$, and $C$ are normal stress, longitudinal reinforcement ratio, size factor, and a coefficient (about 0.12 ), respectively. The $K$ is given by:

$$
K=1+\sqrt{200 / d} \text {, }
$$

where $d$ is the effective depth in mm. It was assumed that cross section of the truss element is equal to $A=B \times \Delta$. The strain energy release rates of Mode $\mathrm{I}, G_{I}$ is expressed as follows [36]: 


$$
G_{I}=\frac{F_{N}\left(x_{1}-x_{2}\right)}{2 B \Delta}=\frac{\sigma_{N}\left(x_{1}-x_{2}\right)}{2}
$$

where $F_{N}, x_{1}$ and $x_{2}$ are nodal force, displacement of node ' 1 ' and ' 2 ' in $x$ direction, respectively. The shear stress of crack in the deep bem is adopted by zhang et al. [37] as:

$\tau_{N}=A+B \sigma_{N}$,

where $A$ and $B$ are the shear cohesive and frictional that are:

$$
\begin{aligned}
& A=0.347 f_{c}^{0.665}, \\
& B=\frac{0.4 f_{c}^{\prime}-0.37-0.347 f_{c}^{\prime 0.665}}{0.25 f_{c}^{\prime}},
\end{aligned}
$$

Therefore, the strain energy release rates for shear, $G_{I I}$, is based on work by Xie et al [18] as follows:

$$
G_{I I}=\frac{\tau_{N}\left(y_{1}-y_{2}\right)}{2},
$$

On the other hand, the $G_{F}$ is the critical fracture energy of concrete deep beam which is equal to [38]:

$$
G_{F}=0.073\left(f_{t}\right)^{0.18} \text {, }
$$

where $f_{t}$ is the tensile strength of concrete. Therefore, when $G_{I}+G_{I I}<G_{F}$, the stiffnesses are equal to Eqs. (1) and (2). When $G_{I}+G_{I I}>G_{F}$, the crack is propagated, the interface element is removed and Eqs. (1) and (2) becomes zero. In addition, to find failure stress, ultimate shear stress by Thomas et al. [39] is used.

Furthermore, a numerical method is developed to model crack propagation based on the mentioned new strain energy release rates in the reinforced concrete deep beam which is flexural-strengthened with CFRP [40,41]. Also, in this study, a computer code was developed specifically to model shear-strengthening of the reinforced concrete deep beam by modifying the crack propagation criteria [42].

\subsubsection{Numerical model based on LEFM}

To compare with the experimental results and FEAPpv based on nonlinear fracture mechanics, the ABAQUS software is used to model crack propagation by conventional cohesive elements. ABAQUS software can only model the crack propagation based on linear fracture mechanics and it cannot capable of simulating nonlinear fracture mechanics. Concrete parameters used for deep beam based on LEFM in ABAQUS are given in Table 1.

Table 1. ABAQUS Parameters of concrete deep beam based LEFM.

\begin{tabular}{ccc}
\hline Parameter & Description & Value \\
\hline$\epsilon$ & Eccentricity & 0.1 \\
\hline$\psi$ & Dilation angle & 56 \\
\hline$\mu$ & $\begin{array}{c}\text { Viscosity } \\
\text { Parameter }\end{array}$ & 0.0001 \\
$\mathrm{~K}$ & $\begin{array}{c}\text { The second } \\
\text { stress invariant/ } \\
\text { tensile meridian }\end{array}$ \\
\hline
\end{tabular}

\subsection{Experimental test of control and CFRP deep beams}


Experimental tests were conducted under static monotonic load to validate the simulation results. Results from both models were compared with the experimental results of three deep beams.

\subsubsection{Specimens}

Figure 2 illustrates the deep beam dimensions which are $500 \mathrm{~mm}$ in depth, 150 $\mathrm{mm}$ in width, and $900 \mathrm{~mm}$ in length. The geometry, supports, and details of the deep beams are also shown in Figure 2. The deep beams were reinforced longitudinally with two $16 \mathrm{~mm}$ diameter steel rebars at bottom and two $12 \mathrm{~mm}$ diameter steel rebars at top with $30 \mathrm{~mm}$ clear concrete cover. The deep beams were not reinforced transversally in order to guarantee the shear failures. Only two stirrups were used out of the shear zone to hold the longitudinal reinforcement in place as shown in Figure 2. The yield strength of the bars was $400 \mathrm{MPa}$ based on the manufacturer report. Average concrete compressive strength was $28 \mathrm{MPa}$ (at 28 days) based on testing three cylinders with diameter of $150 \mathrm{~mm}$ and height of $300 \mathrm{~mm}$. Table 2 shows mix design for the concrete used to cast the deep beams. The mechanical properties of the CFRP plates were found according to ASTM D7565 [43]. The properties of the CFRP plates and steel reinforcement are given in Table 3. B-0, B-1 and B-2 are used to designate the control deep beam, the flexural strengthened and the shear strengthened deep beams, respectively. All the deep beams have the same steel reinforcement as shown in Figure 2.

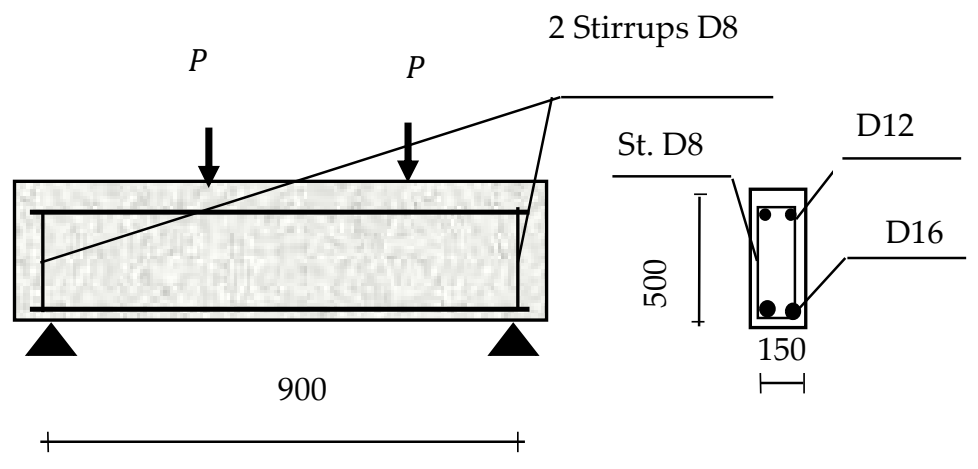

(a)

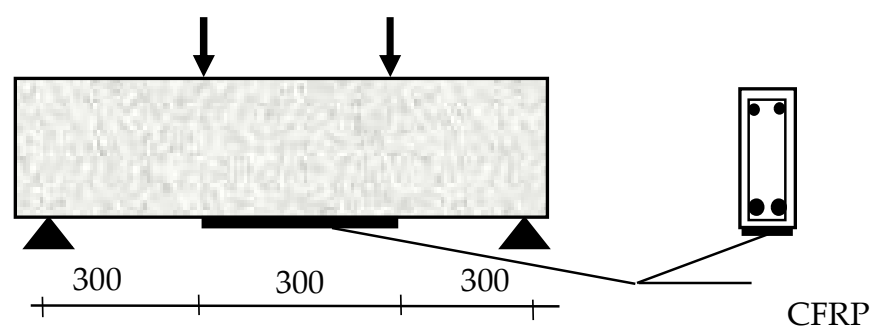


(b)

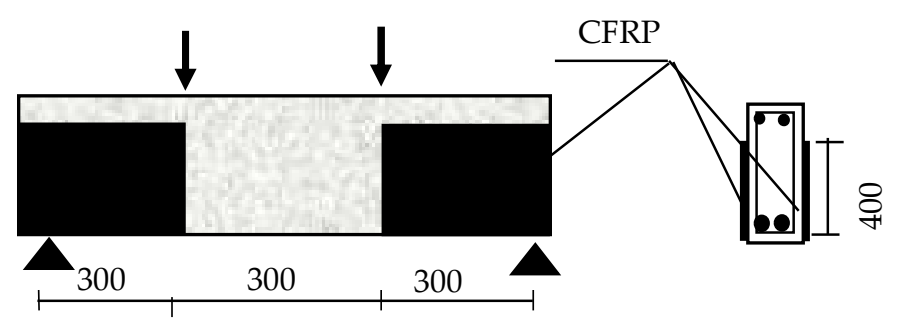

(c)

Figure 2. The detail and boundary condition of deep beams(a) Control deep beam, (b) Flexuralstrengthened and (c) Shear-strengthened by CFRP plates (Unit: $\mathrm{mm}$ ).

Table 2. Mix proportions for the concrete mix.

\begin{tabular}{llllll}
\hline $\begin{array}{l}\text { Mix } \\
\text { design }\end{array}$ & W/C & $\begin{array}{l}\text { Cement } \\
\mathbf{k g} / \mathbf{m}^{3}\end{array}$ & $\begin{array}{l}\text { Water } \\
\mathbf{k g} / \mathbf{m}^{3}\end{array}$ & $\begin{array}{l}\text { Coarse } \\
\text { aggregate } \\
\mathbf{k g} / \mathbf{m}^{3}\end{array}$ & $\begin{array}{l}\text { Fine aggre- } \\
\text { gate } \\
\mathbf{~ k g} / \mathbf{m}^{3}\end{array}$ \\
\hline Concrete & 0.41 & 445.00 & 270 & 1000 & 746 \\
\hline
\end{tabular}

Table 3. Properties of the CFRP plates and steel reinforcement.

\begin{tabular}{lc}
\hline Item & Value \\
\hline Type of CFRP & bidirectional \\
\hline Elastic modulus (GPa) & 250 \\
\hline Strain (\%) & 1.09 \\
\hline Tensile strength (MPa) & 210 \\
\hline Thickness (mm) & 0.8 \\
\hline Epoxy resin Density (kg /l) & 1.7 \\
\hline Epoxy resin tensile strength (MPa) & 14 \\
\hline Modulus of Elasticity of epoxy resin $(\mathrm{GPa})$ & 4 \\
\hline Yield strength (MPa) of steel & 400 \\
\hline Ultimate strength $(\mathrm{MPa})$ of steel & 580 \\
\hline Modulus of elasticity(GPa) of steel & 200 \\
\hline
\end{tabular}

Three plywood formwork (Figure 3(a)) are built to cast the deep beams. Figure 3(b) shows the reinforcement cage layout inside the formwork. After casting (Figure 4), the beams were tested after 28 days in the. The deep beams were simply supported and 
tested under two equal concentrated loads.. For the B-1 deep beam, the CFRP plate was externally bonded at the bottom of the beam. For the B-2 deep beam, the CFRP plate was bonded into the both sides of the deep beam in the shear span. Whereas, the CFRP shear-strengthened plates are not fully wrapped, they are interrupted at a $100 \mathrm{~mm}$ from the top of the beam.

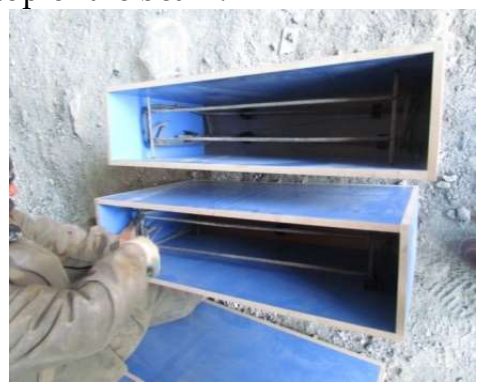

(a)

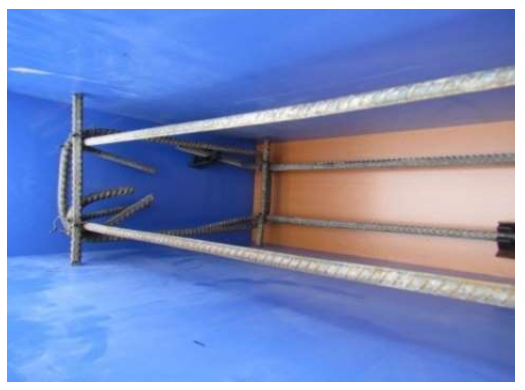

(b)

Figure 3. Detail of bars and three deep beams (a) Frameworks and (b) Bars inside the framework.



Figure 4. Casting by concrete of three deep beam.

\subsubsection{Instrumentation}

A hydraulic jack with $800 \mathrm{kN}$ capacity was used to the deep beam. The mid-span displacements (Figure 5) were recorded by Linear Variable Displacement Transformers (LVDTs). Two strain gauges were attached directly under the CFRP plates and concrete below the load to observe strain. The supports were placed at the bottom of the concrete beams. The applied loads were measured by a load cell. All the measurements were automatically recorded using a data logger.

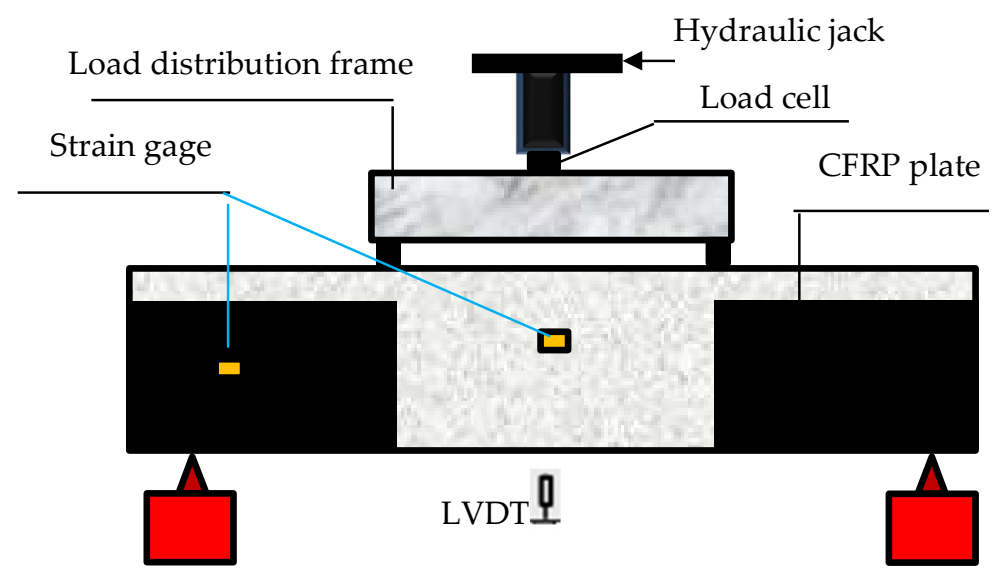


Figure 5. Details of the loading system and measurement schemes.

Before strengthening the specimens with CFRP plates, the concrete surface was cleaned to remove any surface grease. The surfaces of the specimens were further cleaned by grinding and brushing. An epoxy adhesive was uniformly applied in a thin layer on the bonding surfaces as shown in Figure 6. The CFRP was placed over it and pressed firmly by plastic rollers. External strengthening with single-layer CFRP plates has a thickness of $0.8 \mathrm{~mm}$ and an elastic modulus of $250 \mathrm{GPa}$. The ultimate tensile stress of the CFRP plates was $210 \mathrm{GMPa}$.

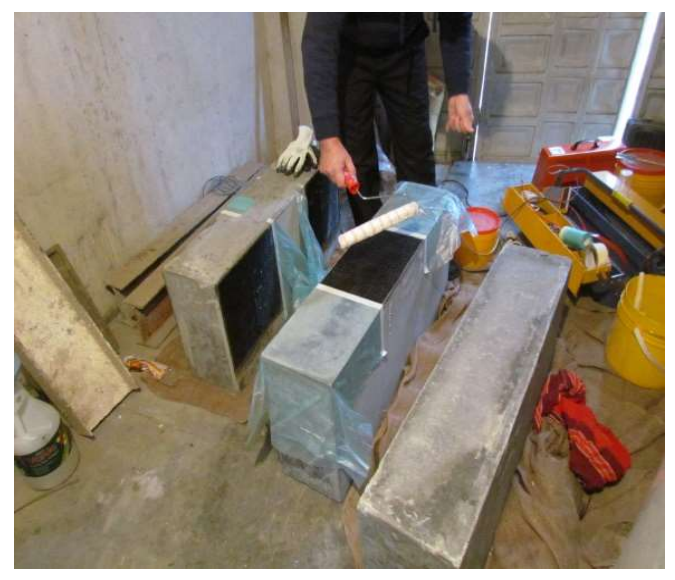

Figure 6. Apply of the CFRP plates on B-1 and B-2 deep beam.

\subsubsection{Test set-up and technique}

Figure 7 illustrates the test setup details for the control beam (B-0), the beam with flexure strengthened by CFRP (B-1), and the beam with shear strengthened by CFRP plates (B-2). A strain gauge was mounted on the surface of concrete to record strain in the concrete. A four-point bending test setup was used to test the beams. One LVDT was set to monitor the displacements under deep beam. A load cell was utilized to measure the applied load. The test was conducted under a gradually increasing monotonic load (at a loading rate of $0.4 \mathrm{~mm} / \mathrm{min}$ ) until beam failure was reached.

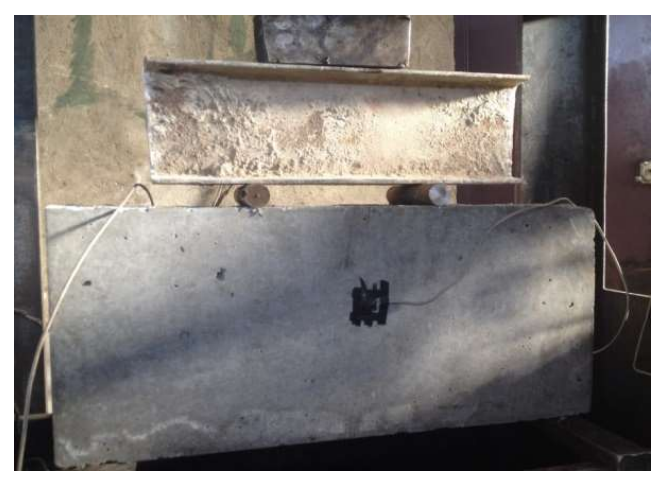

(a) 


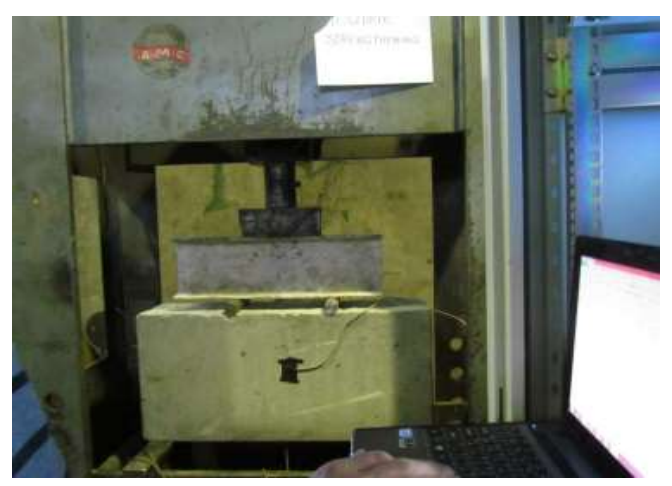

(b)

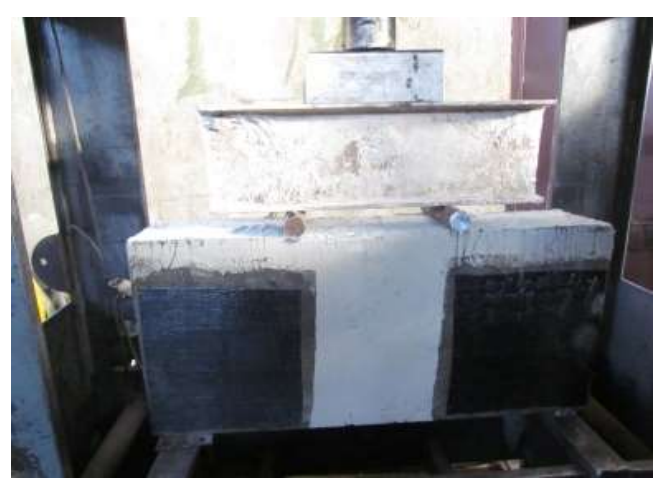

(c)

Figure 7. Deep beams set up before test (a) control, (b) flexural and(c) shearstrengthened.

\section{Results}

This section presents the validation and comparison of crack propagation obtained by the proposed model based on the nonlinear fracture mechanics theory, the experimental results, and ABAQUS software results based on LEFM.

\subsection{Crack propagation in the control beam $(B-0)$}

The control beam was studed first to compare the proposed model with experimental results. A comparison of the proposed model based on nonlinear fracture mechanics theory with the experimental results is shown in Figure 8. A good agreement between the experimental results and proposed model results based on nonlinear fracture mechanics theory was found out for the load-deflection curves in the mid-span, as shown in Figure 8. The load-deflection curves showed nonlinear behavior. The initial stiffness obtained by the nonlinear fracture mechanics model coincides with the stiffness of the beam at the elastic zone, as predicted by the experimental results. The initial stiffness obtained by the linear elastic fracture mechanics model by ABAQUS was over- estimated and had significantly higher stiffness in the mid-span. For the deep beams simulated based on LEFM by ABAQUS, at the same load level, displacements were lower compared to the experimental results. The results of the proposed model based on nonlinear fracture mechanics theory provided an accurate steel yield load point, compared with the experimental results. Thus, the nonlinear fracture mechanics model can detect yield stress in the steel with reasonable accuracy. The most obvious effect of the nonlinear fracture mechanics model on deep beam response can be seen in the plastic zone. The proposed model in the plastic zone corresponds close to the experimental results. Based 
on the nonlinear fracture mechanics model, the failure load is $350.7 \mathrm{kN}$, whereas the experimental result is $331.2 \mathrm{kN}$. Failure load based on the LEFM model by ABAQUS was 401.3. Thus, the nonlinear fracture mechanics model can accurately predict the failure load.

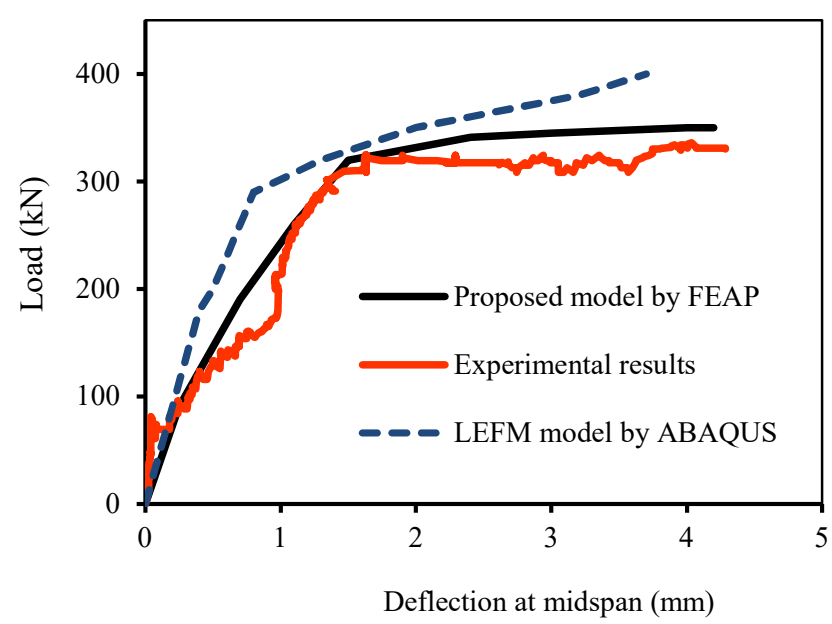

Figure 8. Load-deflection curves of control deep beam (B-0).

Figure 9 shows the crack paths of the control beam, which were modeled using the nonlinear fracture mechanics model. Only half of the beam was modeled by considering symmetry. Figure 10 illustrates the crack path through the experimental test. This crack pattern may be compared with the predicted result shown in Figure 9. The nonlinear fracture mechanics model predicted three cracks within the shear span compared with the three cracks observed in the experimental test. Shear span is the distance between a support and the nearest load point. The nonlinear fracture mechanics model observed one big and one small flexural crack within the flexural zone whereasonly one crack was observed in the experimental result. Flexural span is the distance between the point loads. The agreement between the crack paths obtained in the nonlinear fracture mechanics model and the experimental test is sufficient to justify the validity of the nonlinear fracture mechanics model. The crack patterns obtained by the nonlinear fracture mechanics model and experimental results, were propagated to the last quarter of the section height. Figure 11 shows the crack paths of the control beam simulated using the ABAQUS software based on LEFM. The shear crack near the support cannot be modeled by conventional ABAQUS software. Therefore, the nonlinear fracture mechanics model more objectively predicts crack propagation compared with the ABAQUS software. As shown in figures 9, 10, and 11 11 nodel of control deep beam works better with FEAPpv based on nonlinear fractı $P$ hanics than ABAQUS based on LEFM.

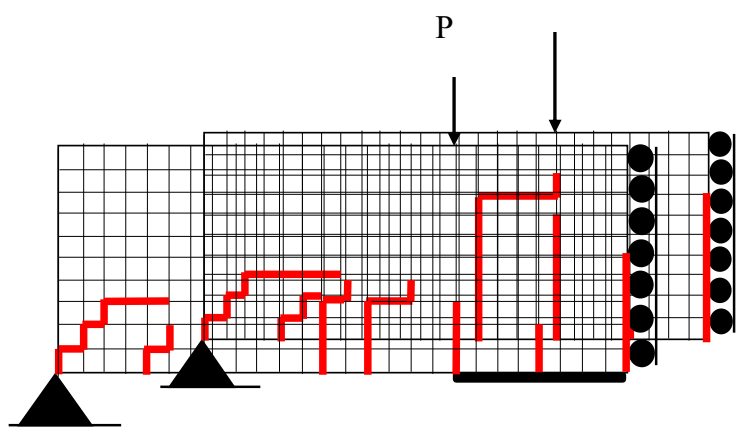

Figure 9. Crack path obtained by nonlinear fracture mechanics model (B-0). 




Figure 10. Crack path observed by experimental test (B-0).

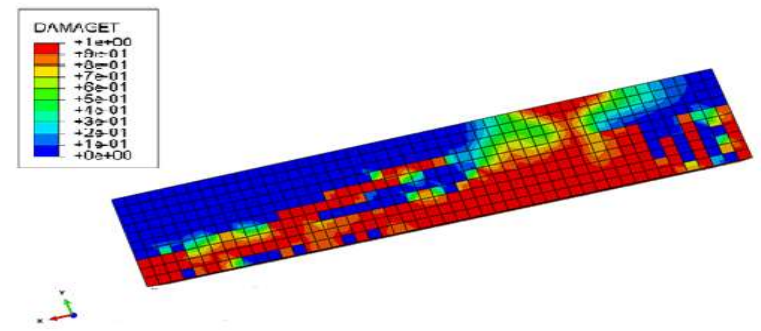

Figure 11. Crack Path by ABAQUS FEA Software(B-0).

Figure 12 compares the load versus the mid-span deflection of the deep beam obtained by the proposed model based on nonlinear fracture mechanics theory, the results of the experimental test, and the ABAQUS software. The results of the proposed model are consistent with the results of the nonlinear fracture michanics. Stiffness of the deep beam predicted based on the LEFM had smaller differences compared with the experimental results. However, the stiffness of the deep beam predicted based on ABAQUS is more than the experimental results stiffness. The steel yield load predicted by LEFM has about $4 \%$ difference compared to the experimental result. However, the steel yield load by ABAQUS software has greater error (31\%) compared to the experimental result, which indicates that it is less capable of estimating the steel yield load. Compared with that in the experimental results, load failure in the poroposed model was predicted within a difference range of $5.6 \%$ to $8 \%$. The load-deflection curve of the nonlinear fracture mechanics model was similar to the experimental results. However, the load-deflection curve by ABAQUS software was higher than the experimental curve. The ABAQUS software results have a greater amount of difference (29.9-39.4\%) compared with the experimental results. Remarkably, the proposed model based on the nonlinear fracture mechanics model could be used to perform analysis of reinforced deep beam flexural-strengthened by CFRP plates. 




Figure 12. Load-deflection of the flexural- strengthened deep beam (B-1)

Figure 13 shows the comparison of crack patterns between the proposed model, the experiment, and the ABAQUS software in the deep beam with flexure strengthened by CFRP plates. The predicted cracking pattern of the proposed model is generally consistent with the experimental observations. In both cases, the flexural cracks were closely spaced near the beam mid-span, as shown in Figures 13(a) and 13(b). Within the shear span, the model predicted two shear-flexural cracks, whereas only one crack was observed in the experiment (left shear span) in half of the beam. The model predicted one shear crack near the support, whereas no crack was observed in the test. The shear cracks may be too small to be noticed in the experimental test. As shown in Figure 13(c), the ABAQUS software cannot simulate this crack pattern because neither the accurate stiffness of the FPZ nor the crack propagation criterion is considered in the software. Flexural crack was observed by the nonlinear fracture mechanics model in the control beam near the mid-span at a load level of $280 \mathrm{kN}$. Whereas, crack of the beam with strengthened in flexure occurred at a relatively higher load level $(300 \mathrm{kN})$ than that for the control beam. Observed flexural crack load for the flexural strengthened deep beam was about $300 \mathrm{kN}$ based on the nonlinear fracture mechanics and the experimental results. The deep beam that strengthened in flexure showed approximately $2 \%$ shorter flexural crack length compared to the control beam. As expected, the behavior of the flexural strengthened deep beam with CFRP plates was slightly changed compared to the control deep beam. Finally, the beam failed because of shear failure with a large shear crack.

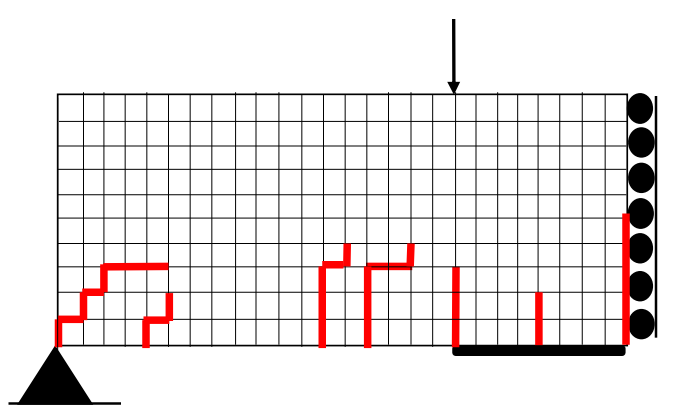

(a) 


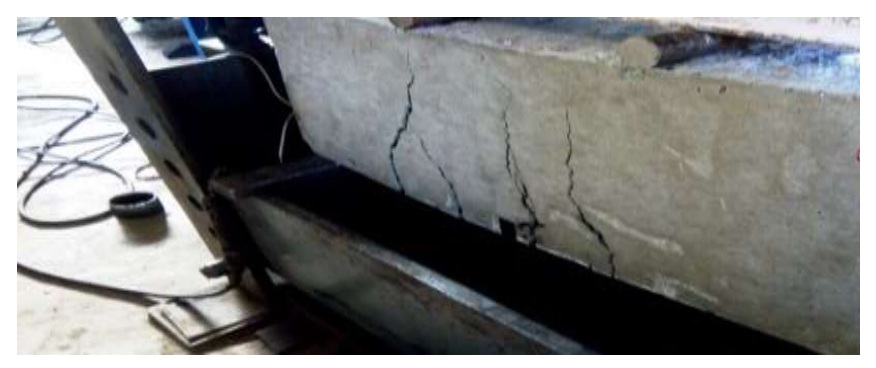

(b)

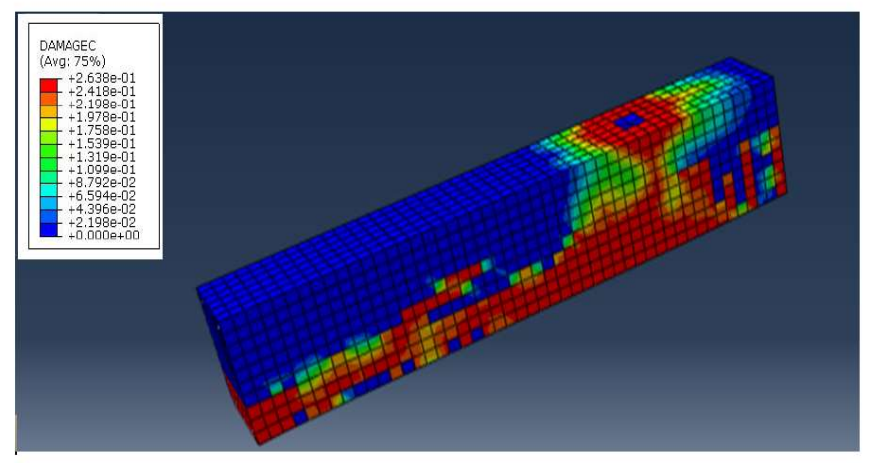

(c)

Figure 13. Crack pattern of the flexural-strengthened deep beam (a) proposed model, (b) experimental, and(c) ABAQUS.

\subsection{Crack propagation in the shear-strengthened deep beam (B-2)}

The load-deflection curves obtained from the experimental test, the nonlinear fracture mechanics model, and the ABAQUS software for the deep beam with shear strengthened by CFRP plates are shown in Figure 14. The results of the proposed model are close to that of the experimental one. This finding indicates that the nonlinear fracture mechanics model is validated by the test results. The yield point of the load-deflection curve in the nonlinear fracture mechanics model is similar to that in the experimental test result (about 3\% difference). However, this point obtained in the LEFM simulations by ABAQUS was higher than that in the experimental test result (about $21 \%$ difference). The accuracy of the proposed model is also confirmed by the close value of the failure load obtained from the proposed model and the test (about $2 \%$ difference at $4 \mathrm{~mm}$ deflection). Also, the stiffness of the beam with shear strengthened by CFRP as analyzed by the ABAQUS software is over- estinated. 


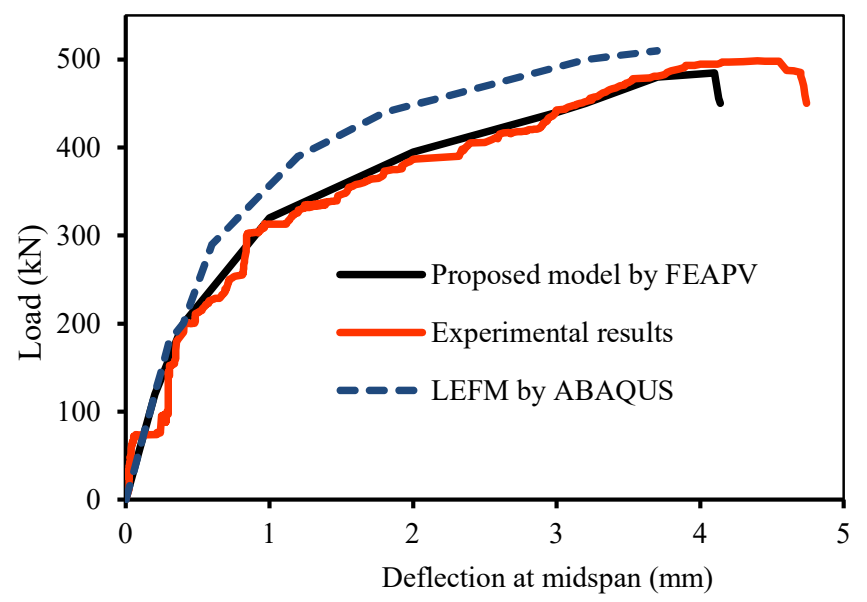

Figure 14. Load-deflection of the shear-strengthened deep beam (B-2).

Figure 15 shows the crack paths obtained by the proposed model, the experimental results, and the cracks predicted in the FEA by ABAQUS. A good agreement is observed for the crack paths predicted by the proposed model compared with the experimental result, as shown in Figures 15(a) and 15(b). Figures 15(a) and 15(b) show that only one flexural crack initiated and propagated towards the loading point. Only one shearflexural crack is observed near the CFRP plate. The shear cracks stopped initation and propagation in the shear span because of the shear strengthened with CFRP plates. The flexural crack began to appear at a load of approximately $240 \mathrm{kN}$. The flexural-shear cracks propagated from the mid-depth of the beam toward the point of the applied load. As the load increased, the flexural-shear crack propagated to the final failure. A comparison of the shear cracks in the beam with strengthened in shear [see Figure 15(a)] and the control beam [see Figure 10] shows that there are more shear cracks in the control beam. The use of CFRP plates affected on and delayed the propagation of the shear crack.

Figure 15(c) shows the crack paths obtained by ABAQUS based on the LEFM. By comparing Figures 15 (a), (b), and (c), the nonlinear fractures mechanics model for the shear-strengthened deep beam with CFRP are comparatively better than the LEFM by ABAQUS.

Figure 16 shows the effect of shear strengthened by CFRP on the crack propagation. Only one small crack formed under the CFRP plate, as shown in Figure 16. CFRP plates delay and control cracking in the beam and confine the crack propagation of concrete. Shear strengthened by CFRP plate reduces the width of cracks in concrete. Figure 16 shows that crack was not observed in the shear span because of the presence of CFRP plates. The crack length was restrained as well.

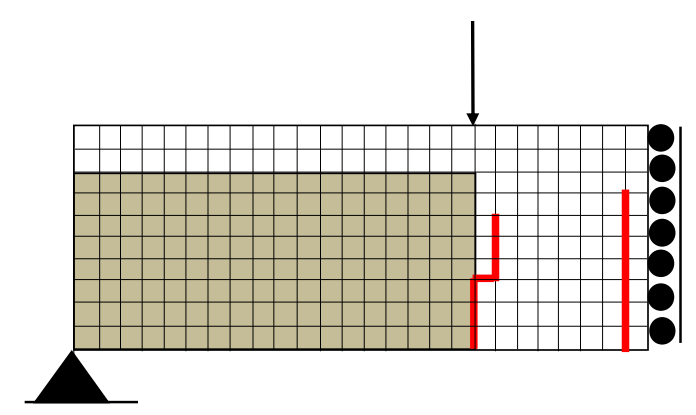


(a)

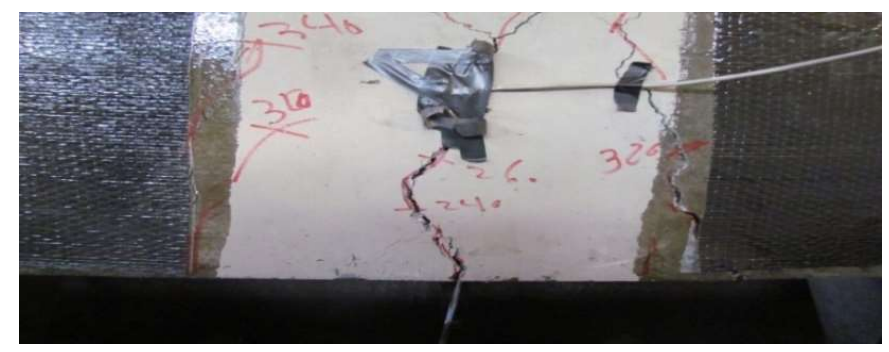

(b)

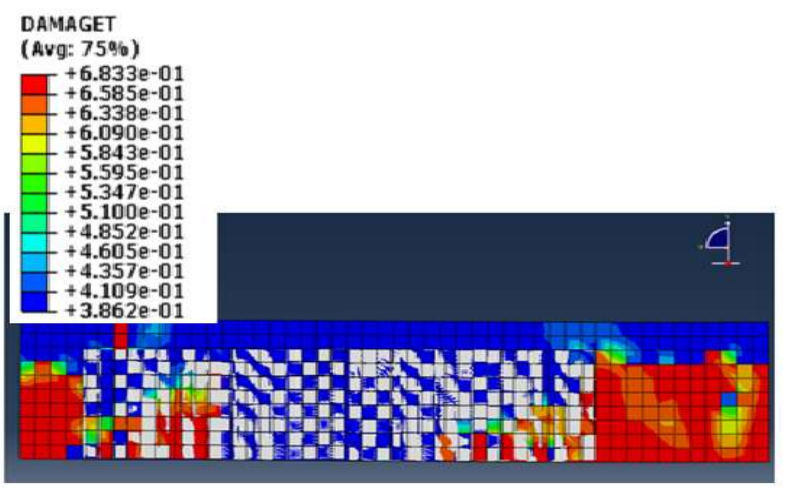

(c)

Figure 15. The crack pattern of the shear-strengthened deep beam (a) proposed model, (b) experimental, and (c) ABAQUS.

In Table 4, some factors such as accuracy of predicted initial stiffness, yielding point (based on the same load), plastic zone, and failure point for each model were compared with the experimental results. The predicted values of initial stiffness, yielding point, and failure point obtained by non-linear fracture mechanics were very close to the experimental results. However, the ABAQUS software results based on LEFM have a greater discrepancy. For example, the steel yielding point in the control deep beam was predicted by non-linear fracture mechanics within a difference of $1.2 \%$. However, the steel yield load by ABAQUS software based on LEFM has a higher difference (13\%) compared to the control beam, which indicates that it is less capable of estimating the steel yield load. The failure loads based on the non-linear fracture mechanics and the experimental results for the shear strengthened deep beam, were about 485 and $498 \mathrm{kN}$ corresponding to mid-span displacements of 4.1 and $4.5 \mathrm{~mm}$, respectively. However, these values for the model based on LEFM were equal to $510 \mathrm{kN}$ with mid-span deflections of $3.7 \mathrm{~mm}$. For the shear strengthened deep beam (B-2), delamination of the CFRP plates was evident based on the non-linear fracture mechanics model and the experimental results. However, the model based on LEFM showed that failure occurs because of the rupture of the CFRP plates on the shear span.

Table 4: Comparison both model with results of experimental (at the same load) 


\begin{tabular}{|c|c|c|c|c|c|c|c|}
\hline Deep beam & Model & $\begin{array}{c}\text { stiffness } \\
(\%)\end{array}$ & $\begin{array}{c}\text { Yielding } \\
(\%)\end{array}$ & $\begin{array}{c}\text { Plastic } \\
\text { zone (\%) }\end{array}$ & $\begin{array}{l}\text { Failure load } \\
\qquad(\%)\end{array}$ & $\begin{array}{l}\text { Failure mode } \\
\text { by models }\end{array}$ & $\begin{array}{c}\text { Failure mode by } \\
\text { experimental }\end{array}$ \\
\hline & Proposed model & & & & & & \multirow{3}{*}{ Shear } \\
\hline & & $2-6$ & 1.2 & $9-11$ & 6.3 & Shear & \\
\hline Control (B-0) & LEFM & $12-19$ & 40 & $16-24$ & 23.6 & Shear & \\
\hline \multirow{2}{*}{$\begin{array}{l}\text { Flexural Strength- } \\
\text { ening (B-1) }\end{array}$} & Proposed model & $1-4$ & 4 & $5-7$ & $5.6-8.0$ & Shear & \multirow{2}{*}{ Shear } \\
\hline & LEFM & $10-16$ & 31.1 & $14-20$ & $29.9-39.4$ & Shear & \\
\hline \multirow{2}{*}{$\begin{array}{l}\text { Shear Strengthening } \\
\text { (B-2) }\end{array}$} & Proposed model & $6-10$ & 3 & $1-3$ & 2.6 & Delamination & \multirow{2}{*}{$\begin{array}{l}\text { CFRP Delami- } \\
\text { nation }\end{array}$} \\
\hline & LEFM & $22-35$ & 21 & $34-53$ & 25.1 & CFRP rupture & \\
\hline
\end{tabular}

In Table 5, the energy absorption (the area under the load-deflection curve) is listed for each deep beam at failure load. The calculated energy absorptions for the control deep beam were 987, 1029, and $1154 \mathrm{kN} . \mathrm{mm}$ based on the experimental, the proposed model, and the LEFM results, respectively. The energy absorption for the control deep beam obtained from the experimental results is slightly lower than that found by the proposed model. Also, for the strengthened deep beams in shear, the energy absorption obtained by LEFM is much higher than that of the experimental results and the proposed model. The shear strengthened deep beam showed an increase in the energy absorption up to $67.1 \%$ compared to the control deep beam. The experimental compressive strain for the shear-strengthened deep beam was greater than the control deep beam compressive strain due to shear strengthening. The compressive strain reported for the shearstrengthened deep beam is about 0.00318 . In both the models and the experimental results, the control deep beam had the lowest concrete compressive strain compared to the other two deep beams. The shear strengthened deep beam simulated by proposed model showed an increase in the compressive strain of $1.2 \%$ compared to the experimental results, while this increase was $10.4 \%$ for the deep beam modeled by LEFM. Therefore, the nonlinear fracture mechanics model has shown better performance for estimating concrete compressive strain compared to the LEFM model.

Table 5. Energy absorption and compressive strain in the concrete

\begin{tabular}{|c|c|c|c|}
\hline Model & & $\begin{array}{c}\text { Energy } \\
\text { absorption } \\
\text { (kN.mm) }\end{array}$ & $\begin{array}{l}\text { Compressiv } \\
\text { e strain in } \\
\text { the concrete }\end{array}$ \\
\hline \multirow{4}{*}{ Control (B-0) } & Experimental & 987 & 0.00301 \\
\hline & Nonlinear fracture & & \\
\hline & & 1029 & 0.00318 \\
\hline & LEFM & 1154 & 0.00324 \\
\hline \multirow{3}{*}{$\begin{array}{c}\text { Flexural } \\
\text { Strengthening } \\
\text { (B-1) }\end{array}$} & Experimental & 1055 & 0.00321 \\
\hline & Nonlinear fracture & 1089 & 0.000335 \\
\hline & LEFM & 1257 & 0.00355 \\
\hline \multirow{2}{*}{$\begin{array}{c}\text { Shear } \\
\text { Strengthening }\end{array}$} & Experimental & 1650 & 0.00314 \\
\hline & Nonlinear fracture & 1573 & 0.00318 \\
\hline
\end{tabular}


(B-2)

LEFM

1439

0.00347

\section{Discussion}

In this study, a numerical model was developed to predict crack propagation that occurs in RC deep beams strengthened by CFRP under static monotonic load. The results were compared to experiment results, and it was shown that the present numerical results were close to the experimental test results. The following topics are suggested for future work:

a) In the present study a nonlinear material interface element was assumed based on small displacement. It would be interesting to reformulate the based proposed model on large deformation.

b) It is recommended to study creep action on deep beam strengthened by FRP and to consider the effect of environmental condition.

c) To study the fracture of beams in shear by internally reinforced with FRP bars.

d) Similar experimental studies using high performance concrete and light-weight concrete can be considered for future study.

\section{Conclusions}

In this study, two models for reinforced concrete deep beam strengthened with CFRP plates were proposed to predict the fracture behavior of a deep beam. One of the models is based on nonlinear fracture mechanics by FEAPpv. Also, a new energy release rate based on nonlinear fracture mechanics theory was formulated. The DCZM was developed in deep beams and the crack propagation criteria were proposed. Another model is based on linear elastic fracture mechanics by ABAQUS software. Experimental testing on reinforced concrete deep beams strengthened with CFRP plates was carried out to compare with the models.

The proposed model can reasonably predict the experimental results in terms of stiffness, yielding load, plastic zone, and failure load. While, the ABAQUS results in the mentioned parts were far from the experimental results. For example, the failure load of the shear-strengthened deep beam was predicted by proposed model with $6.3 \%$ difference compared to the experimental result. However, the failure load predicted by ABAQUS software based on LEFM has a greater difference (25.1\%) with the experimental result. The proposed model captured the crack patterns of the strengthened reinforced concrete deep beam with CFRP plates quite satisfactorily compared to the experimental observations. For the shear strengthened deep beams, the energy absorption obtained by LEFM was much greater than those of the experimental results and the proposed model. Furthermore, the shear strengthened deep beam simulated by the proposed model showed an increase in the compressive strain of $1.2 \%$ compared to the experimental results, while this increase was $10.4 \%$ for the deep beam modeled by LEFM. Therefore, the nonlinear fracture mechanics model is a reasonable choice for simulating the fracture mechanics of the reinforced concrete deep beam strengthened with CFRP plates.

Author Contributions: Conceptualization, S.S., H.K., W. A. and A. M..; methodology, S.S., H. K., S.S. and W. A.; software, S.S., H. K., S.S. and W. A.; validation, A.M.; formal analysis, S.S., H. K., S.S. and W. A.; investigation, S.S., H. K., S.S. and W. A.; resources, A.M.; data curation, S.S., H. K., S.S. and W. A.; writing-original draft preparation, S.S., H. K., S.S. and W. A.; writing-review and editing, S.S., H. K., S.S., W. A. and A.M. ;visualization, S.S., H. K., S.S. and W. A.; supervision, S.S. and A.M.; project administration, A.M.; funding acquisition, A.M. All authors have read and agreed to the published version of the manuscript.

Funding: The authors wish to gratefully acknowledge the Alexander von Humboldt Foundation for the funding support of this study under project number AvH0001AB32. 
Acknowledgments: Support of Alexander von Humboldt Foundation is acknowledged.

Conflicts of Interest: The authors declare no conflict of interest

\section{References}

1. 1. El-Sayed, A. K.; Shuraim, A. B. Experimental verification of strut and tie model for HSC deep beams without shear reinforcement. Engineering Structures 2016, 17, 71-85.

2. 2. Mohamed, K.; Farghaly, A. S.; Benmokrane, B.; Neale, K. W. Nonlinear finite-element analysis for the behavior prediction and strut efficiency factor of GFRP-reinforced concrete deep beams. Engineering Structures 2017, 137, 145-161.

3. 3. Isojeh, B.; Zeghayar, M. E. High-cycle fatigue life prediction of reinforced concrete deep beams. Engineering Structures 2017, 150, 12-24.

4. 4. Kim, D. J.; Lee, J.; Lee, Y. H. Effectiveness factor of strut-and-tie model for concrete deep beams reinforced with FRP rebars. Composites Part B: Engineering 2014.

5. 5. Dhahir, M. K. Shear strength of FRP reinforced deep beams without web reinforcement. Composite Structures 2017, $165,223-232$.

6. 6. Andermatt, M. F.; Lubell, A. S. Behavior of concrete deep beams reinforced with internal fiber-reinforced polymer-experimental study. ACI Structural Journal 2013, 110 (4), 585-594.

7. 7. Rarani, M. H.; Sayedain, M. Finite element modeling strategies for 2D and 3D delamination propagation in composite DCB specimens using VCCT, CZM and XFEM approaches. Theoretical and Applied Fracture Mechanics 2019, $103,102246$.

8. 8. Kumar, S.; Barai, S. V. Concrete fracture models and applications; Springer: Berlin Heidelberg, 2011.

9. 9. Esfahani, M. R. Fracture mechanics of concrete; Tehran Polytechnic press: Tehran Iran, 2007.

10. 10.Kaplan, M. E. Crack propagation and the fracture concrete. ACI Journal 1961, 58 (5), 591- 610.

11. 11.Dong, W.; Yang, D.; Kastiukas, G.; Zhang, B. Experimental and numerical investigations on fracture process zone of rock-concrete interface. Fatigue and Fracture of Engineering Materials and Structures 2016, 40 (5), 820-835.

12. 12.Tryding, J.; Ristinmaa, M. Normalization of cohesive laws for quasi-brittle materials. Engineering Fracture Mechanics 2017, In Press.

13. 13.Kurumatani, M.; Soma, Y.; Terada, K. Simulations of cohesive fracture behavior of reinforced concrete by a fracture-mechanics-based damage model. Engineering Fracture Mechanics 2019, 206.

14. 14.Fakoorr, M.; Shahsava, S. Fracture assessment of cracked composite materials: Progress in models and criteria. Theoretical and Applied Fracture Mechanics 2020, 105, 102430.

15. 15.Xie, M.; Gerstle, W. H. Energy-based cohesive crack propagation modeling. Journal of Engineering Mechanics, ASCE 1995, 121 (12), 1349-1458.

16. 16.Ohno, K.; Uji, K.; Ueno, A.; Ohtsu, M. Fracture process zone in notched concrete beam under three-point bending by acoustic emission. Construction and Building Materials 2014.

17. 17.Xie, D.; Biggers, S. B. J. Progressive crack growth analysis using interface element based on the virtual crack closure technique. Finite Elements in Analysis and Design 2006, 42 (11), 977 - 984.

18. 18.Xie, D.; Waas, A. M. Discrete cohesive zone model for mixed-mode fracture using finite element analysis. Engineering Fracture Mechanics 2006 , 73 (13), 1783-1796.

19. 19.Shahbazpanahi, S.; Paknahad, M. Simulation of the Mode I fracture of concrete beam with cohesive models. Journal of Computational Applied Mechanics 2017, 48 (2), 207-216.

20. 20.Bruno, D.; Greco, F. A fracture-ALE formulation to predict dynamic debonding in FRP strengthened concrete beams. Composites Part B: Engineering 2013, 46, 46-60.

21. 21.Zheng. , J.; Dai, J.; Fan, X. Fracture analysis of frp-plated notched concrete beams subjected to three-point bending. Journal of Engineering Mechanics 2015, 142 (3), 1-10.

22. 22.Karim, H.; Sheikh, M. N.; Hadi, M. N. S. Axial load-axial deformation behaviour of circular concrete columns reinforced with GFRP bars and helices. Construction and Building Materials 2016, 112, 1147-1157.

23. 23.Shahbazpanahi, S.; Ali, H. F. H. Development of fracture mechanics model of beam retrofitted with CFRP plate subjected to cyclic loading. Journal of Mechanics of Materials and Structures 2019, 14 (3), 413-427.

24. 24.Okahashi, Y.; Pantelides, C. O. Strut-and-tie model for interior RC beam-column joints with substandard details retrofitted with CFRP jackets. Composite Structures 2017, 165, 1-8.

25. 25. Ashour, A. F.; Yang, K. H. Application of plasticity theory to reinforced concrete deep Beams-A Review. Magazine of Concrete Research 2008, 60 (9), 657-664.

26. 26.Zhang, N.; Tan, K. Effects of support settlement on continuous deep beams and STM modeling. Engineering Structures 2010, $32(2), 361-72$.

27. 27.Taylor, L. R. FEAPpv source, A finite element analysis program, Personal version; University of California: Berkeley, 2009.

28. 28.Spada, A.; Giambanco, G.; Rizzo, P. Elastoplastic damaging model for adhesive anchor systems. I: Theoretical formulation and numerical implementation. American Society of Civil Engineers 2011, 137 (12), 854.

29. 29. Yang, W. G.; Xiang, H. J. A new approach for the simulation of cementitious materials. Journal of Mechanical Science and Technology 2012, 26 (1), 45-51. 
30. 30.Yang, W. G.; Guo, Z. Q.; Xiang, H. J. Numerical simulation of cementitious granular materials. Science and Engineering of Composite Materials 2012, 19 (1), 9-17.

31. 31.Li, H. N.; Li, M. Experimental and numerical study on dynamic properties of RC beam. Magazine of Concrete Research 2013, 65 (12), $744-756$.

32. 32.Zhang, H. M.; Zhang, L. X. Numerical simulation of fluid-structure interaction with water hammer in a vertical penstock subjected to high water head. Advanced Materials Research 2014, 860, 1530-1534.

33. 33.Karavelic, E.; Nikolic, M.; Ibrahimbegovic, A.; Kurtovic, A. Concrete meso-scale model with full set of 3D failure modes with modes with random distribution of aggregate and cement phase. Part I: Formulation and numerical implementation. Computer Methods in Applied Mechanics and Engineering 2019, 344, 1051-1072.

34. 34.Thomas, J.; Ramadassb, S. Prediction of the load and deflection response of concrete deep beams reinforced with FRP bars. Mechanics of Advanced Materials and Structures 2019, 1-24.

35. 35.Walraven, J. C. Fracture mechanics of concrete and its role in explaining structural behaviour. 6th International conference on fracture mechanics of concrete and concrete structures, London, 2007; pp 1265-1275.

36. 36.Xie, D.; Salvi, A. G.; Sun, C.; Waas, A. M.; Caliskan, A. I. Discrete Cohesive Zone Model to Simulate Static Fracture in 2D Triaxially Braided Carbon Fiber Composites. Journal of Composite Materials 2006, 40(22)2025-40(22)2046.

37. 37.Zhang, T.; Visintin, P.; Oehlers, D. J. Shear strength of RC beams without web reinforcement. Australian Journal of Structural Engineering 2016, 17 (1), 87-96.

38. 38.Demir, A.; Ozturk, H.; Dok, G. 3D numerical modeling of rc deep beam behavior by nonlinear finite element analysis. Disaster Science and Engineering 216, 2 (1), 13-18.

39. 39.Thomas, J.; Ramadass,. Prediction of the load and deflection response of concrete deep beams reinforced with FRP bars. Mechanics of Advanced Materials and Structures 2019, In press.

40. 40.Said, A. M.; Nehdi, M. L. Use of FRP for RC frames in seismic zones:Part I. Evaluation of FRP beam-column joint rehabilitation techniques. Applied Composite Materials 2004, 11, 205-226.

41. 41.Shahbazpanahi, S.; Abang, A. A. A.; Kamgar, A.; Farzadnia, N. Fracture mechanic modeling of fiber reinforced polymer shear-strengthened reinforced concrete beam. Composites: Part B 2014, 68, 113-120.

42. 42.Shahbazpanahi, S.; Ali, A. A. A.; Aznieta, F. N.; Kamgar, A.; Farzadnia, N. A simple and practical model for FRP-reinforced cracked beam. European Journal of Environmental and Civil Engineering 2013, 18 (3), 1-14.

43. 43. ASTM D7565 Standard test method for determining tensile properties of fiber reinforced polymer matrix composites used for strengthening of civil structures. ASTM International, West Conshohocken, PA 2017. 